\title{
Heidegger: da filosofia fenomenológica à fenomenologia da religião ${ }^{1}$
}

\author{
Heidegger: from phenomenological \\ philosophy to phenomenology of religion
}

\author{
Renato Kirchner \\ "Herkunft aber bleibt stets Zukunft." (Heidegger)
}

RESUMO

Durante os anos que antecederam a concepção e elaboração de Ser e tempo, Martin Heidegger (1889-1976) distancia-se gradativamente da teologia e da filosofia tradicional e aproxima-se da filosofia fenomenológica de Edmund Husserl (18591938). Diante disso, numa perspectiva mais ampla, o propósito do presente artigo consiste em evidenciar como Heidegger se aproximou da filosofia fenomenológica e, numa perspectiva mais estrita, objetiva-se entender o modo pelo qual o filósofo de Messkirch buscou forjar e estabelecer uma peculiar fenomenologia da religiáo. Nosso escopo principal, porém, consiste em apresentar sucintamente a concepção heideggeriana de fenomenologia da religião à medida que se vincula à experiência fática da vida.

PALAVRAS-CHAVE: Teologia. Filosofia fenomenológica. Fenomenologia da religiáo. Experiência fática da vida.

\section{ABSTRACT}

Throughout years leading the design and development of Being and Time, Martin Heidegger (1889-1976) distances himself gradually from theology and traditional

Recebido em 24/11/2014. Aprovado em 02/01/2015.

Doutor em Filosofia pela Universidade Federal do Rio de Janeiro, atualmente é professor e pesquisador do programa de mestrado em Ciências da Religiấo na Pontifícia Universidade Católica de Campinas. País de origem: Brasil. E-mail: renatokirchner@puc-campinas.edu.br. 
philosophy and approaches to the phenomenological philosophy of Edmund Husserl (1859-1938). Thus, in a broader perspective, the purpose of this article is to show how Heidegger approached the phenomenological philosophy and, in a strict perspective, we seek to understand the way the Messkirch philosopher sought to create and establish a peculiar phenomenology of religion. Our main aim, however, is to briefly present Heidegger's conception of phenomenology of religion as it binds to the factual experience of life.

KEYWORDS: Theology. Phenomenological philosophy. Phenomenology of religion. Factual experience of life.

\section{Introdução}

Embora a vida e a obra de Martin Heidegger sejam motivo de ocupação de numerosos pesquisadores pelo mundo afora, o fato é que continua sendo estudado e, provavelmente, isso se perpetuará por um longo tempo. Constatado isso, imprescindível perguntar: por que esse fenômeno se dá com Heidegger? Há, de certo, várias maneias de responder a esta pergunta. A resposta mais imediata seria: ora, a obra completa (Gesamtausgabe) foi sequer totalmente publicada. Outra resposta, sobretudo aos já leitores e estudiosos da obra heideggeriana, poderia ser: cada volume da obra completa dá motivo para uma infinidade de pesquisas possíveis, justamente porque o filósofo está, incessantemente, fazendo um trabalho interpretativo de desconstrução e reconstrução da história do pensamento ocidental que, além disso, acaba tendo inflexóes fundamentais sobre muitas outras áreas do conhecimento humano. Contudo, talvez devêssemos encarar o conjunto da obra heideggeriana numa outra perspectiva: ela mesma é um programa de uma problemática fundamental! (cf. Escudero, 2008 e 2010). O fato do filósofo mesmo ter programado, isto é, planejado a sequência da publicação de sua obra completa poderia ser vista como uma indicação de algo mais fundamental? Procurando levar a sério esta pergunta, talvez seja conveniente ter presente uma passagem do último parágrafo de Ser e tempo que, como sabemos desde o início dos anos 50, permanecerá um torso:

Trata-se de buscar e de percorrer um caminho para o esclarecimento da questão da ontologia fundamental. Somente após tê-lo percorrido é que 
se poderá decidir se ele é o único ou, simplesmente, o correto. Por nem sequer ter sido desencadeado, o combate em torno da interpretação de ser não se pode dar por terminado. Por fim, esse combate não pode ser desencadeado 'com um estalar de dedos', mas exige uma mobilização. Exclusivamente para isso é que a presente investigação está a caminho. Onde ela está? (Heidegger, 2006, p. 535).

Para nossos propósitos introdutórios, convém tirar uma consequência muito simples desta citação: em perspectiva heideggeriana, toda tentativa de pensar está tão somente e apenas "a caminho". De fato, a única prova do "a caminho" (unterwegs) consiste em de fato estarmos dispostos "a percorrer um caminho" (einem Weg zu gehen).

$\mathrm{O}$ que segue tematizado, sob o título "Da filosofia fenomenológica à fenomenologia da religiāo", é uma tentativa de lançar uma luz sobre uma frase de Heidegger citada a propósito de epígrafe: "Ora, proveniência é sempre porvir" ("Herkunft aber bleibt stets Zukunft") (Heidegger, 2003, p. 79). O contexto em que esta frase é citada dá a entender que o filósofo de Messkirch jamais abandonou as origens, também suas origens religiosas. Contudo, por que muitas vezes sua postura filosófica é vista como ateia? Em que medida foi Heidegger ateu? É o que este artigo de alguma maneira procurará evidenciar percorrendo as seguintes etapas: 1 . Da teologia à filosofia fenomenológica; 2. Da filosofia fenomenológica à fenomenologia da religião; 3. Análise fenomenológica da experiência fática da vida.

\section{Da teologia à filosofia fenomenológica}

Martin Heidegger nasceu aos 26 de setembro de 1889 numa pequena cidade chamada Messkirch, na Floresta Negra, sul da Alemanha. Seu pai, Friedrich, era mestre carpinteiro e servia de sacristão na Igreja de São Martinho. A mãe, Johanna, da família Kempf, era também, como o pai, de confissão católica. Na escola comunal de Messkirch cursou as primeiras séries e, posteriormente, as demais séries do ensino fundamental em Constança e o ensino 
médio no Bertholdgymsasium de Friburgo, concluído em 1909. De 1909 a 1914, estudou na Universidade de Friburgo. No primeiro semestre, frequentou os cursos de teologia e filosofia, desde 1911, sobretudo os de filosofia, matemática e ciências naturais e, no último semestre, os cursos de história. Doutorou-se sob a direção de Heinrich Rickert, em 1914, com a tese $A$ doutrino do juizo no psicologismo (Die Lehre vom Urteil im Psychologismus). Em 1915, habilitou-se para o magistério num concurso, para a Universidade de Friburgo, com a tese $A$ doutrina das categorias e da significação de Duns Escoto (Die Kategorien- und Bedeutungslehre des Duns Scotus), cuja publicação data de 1916. De 1916 a 1923, deu cursos e seminários em Friburgo na qualidade de professor assistente. De 1923 a 1928 foi transferido, como professor titular de filosofia, para a Universidade de Marburgo. Resulta desse período sua obra principal Ser e tempo (Sein und Zeit), publicada pela primeira vez, em 1927, no Anuário de filosofia e investigação fenomenológica (Jahrbuch für Philosophie und phänomenologische Forschung), fundado por Edmund Husserl em $1913^{3}$. O Anuário desempenhou um papel todo particular de modo que muitas obras filosóficas do início do século XX pudessem vir a público $^{4}$. Em 1928, Heidegger retornou para Friburgo no intuito de suceder a Edmund Husserl na cadeira de filosofia. Em maio de 1933, foi eleito reitor da Universidade de Friburgo, sendo que nove meses depois, em fevereiro de 1934, renunciou. No outono de 1944, foi mobilizado para trabalhar nas fortificações do Reno, sendo, logo em seguida, enviado para o campo de batalha. Em 1945, foi proibido de lecionar pelas autoridades aliadas de ocupação. Em 1951, foi reintegrado à universidade e, no ano seguinte, tornou-se professor

Segundo Sokolowski, "muitas monografias alemãs importantes apareceram nesse Anuário, incluindo Ser e tempo, de Heidegger, Ideias I e Lógica formal e transcendental, do próprio Husserl, Formalismo na ética, de Max Scheler, e obras de Adolf Reinach, Alexander Pfänder, Oskar Becker e Moritz Geiger. Um total de onze volumes, alguns dos quais contendo mais do que uma obra, foram publicados nessa série entre 1913 e 1930. A última foi um estudo de Eugen Fink sob o título Vergegenwärtigung und Bild (Representaçấo e imagem)" (Sokolowski, 2012, p. 224).

Numa observação preliminar à sétima ediçáo, de 1953, Heidegger mesmo registra: "O tratado Ser e tempo foi publicado pela primeira vez no Jahrbuch für Philosophie und phänomenologische Forschung, v. VIII, editado por Edmund Husserl e, ao mesmo tempo, em separata" (Heidegger, 2006, p. 33). 
emérito. Em 1957/58, encerrou sua carreira universitária. Faleceu no dia 26 de maio de 1976, em Friburgo, aos 86 anos de idade.

Toda tentativa de fazer um apanhado da trajetória do filósofo como o que acabamos de fazer, porém, tende a ficar distante de obra propriamente dita. Por isso, para entender a estatura filosófica alcançada por Heidegger pressupóe que sejamos também capazes de acompanhar minimamente como ele se apropriou de um grande número de autores e obras da tradição com os quais se confrontou e deteve longamente. Cabe destacar, de saída, algumas referências reconhecidas explicitamente pelo filósofo em textos tardios como é o caso: De uma conversa da linguagem entre um japonês e um pensador (Aus einem Gesprach von der Sprache. Zwischen einem Japaner und einem Fragenden), de 1953-1954 e Meu caminho para a fenomenologia (Mein Weg in die Phänomenologie), de $1963^{5}$.

De fato, três obras exerceram sobre o jovem Heidegger uma influência decisiva: as Investigaçôes lógicas (Logische Untersuchungen), de Edmund Husserl, publicadas pela primeira vez, em dois volumes, entre 1900 e 1901; a dissertação de Franz Brentano, Sobre o significado múltiplo do ente segundo Aristóteles (Von der Mannigfachen Bedeutung des Seienden nach Aristoteles), publicada em 1862; bem como Sobre o ser: Compêndio de ontologia (Vom Sein: Abriss der Ontologie), de Carl Braig, publicado em 1896. Em Mein Weg in die Phänomenologie, Heidegger mesmo reconhece que, em 1907, "o principal auxílio, nas minhas desajeitadas tentativas para penetrar na filosofia”, estavam voltadas para Brentano. E, mais adiante: "Após quatro semestres, abandonei o estudo teológico e dediquei-me inteiramente à filosofia” (Heidegger, 2009, p. 85-86). Importante observar que, a

\footnotetext{
Mesmo tardios, são dois textos importantes para compreender o percurso fenomenológico de Heidegger. Muitos dos nomes que se tornariam notórios na seara filosófica do século XX, foram ex-alunos de Heidegger particularmente nos anos 20, entre os quais: Hannah Arendt, Hans Jonas e Hans-Georg Gadamer. Neste último, por exemplo, podemos encontrar inúmeros registros importantes dessa trajetória (Gadamer, 2004 e 2009). Além disso, não foram poucos os estudiosos que se ocuparam em compreender a caminhada de Heidegger, dos quais destacamos quatro: A via do pensamento de Martin Heidegger (Der Denkweg Martin Heideggers) (Pöggeler, 2001); Martin Heidegger: a caminho da sua biografia (Martin Heidegger: Unterwegs zu seiner Biographie) (Ott, 2000); Heidegger: um mestre na Alemanha entre o bem e o mal (Ein Meister aus Deuschland. Martin Heidegger und seine Zeit) (Safranski, 2000); Heidegger e o seu século: Tempo do ser, tempo da história (Heidegger et son siècle: Temps de l'Etre, temps de l'histoire) (Barash, 1997).
} 
caminhos de uma formação teológica, Heidegger tenha sido atraído cada vez mais para algumas obras filosóficas ${ }^{6}$. De fato, o domínio da teologia vai sendo aos poucos abandonado, em vista do que era possível acompanhar nos seminários de Heinrich Rickert e pelos textos de Emil Lask. Todavia, o que atraía mesmo sua atenção eram as Investigaçóes lógicas. É o que podemos ler nesta passagem:

Esta situação obrigou-me a voltar à obra de Husserl. Entretanto, também esta abordagem repetida permaneceu insatisfatória, pois não conseguia superar uma dificuldade capital. Esta referia-se à simples questáo de como se deveriam realizar os modos de proceder do pensamento denominado 'fenomenologia'. O elemento inquietante desta questáo resultava da ambiguidade que a obra de Husserl revela à primeira vista (Heidegger, 2009, p. 87).

Esta passagem dá o tom e define a atenção de Heidegger ao longo dos anos de sua formação acadêmica, ou seja, embora houvesse uma promessa de o estudante seguir uma carreira eclesiástica (Ott, 2000) ${ }^{7}$, aos poucos, porém, o jovem Heidegger foi voltando todas as suas energias para a filosofia. Naturalmente, filosofia significava, então, fenomenologia! De modo que o próprio Husserl dizia naqueles anos: "A fenomenologia somos eu e Heidegger" (citando Gadamer, cf. Stein, 2001, p. 143). Porém, para Heidegger, o que poderia significar "fenomenologia" por volta dos anos em que atuava como professor em Marburgo? Trata-se de uma pergunta nada fácil de responder e, muito menos, objetivamente. Como veremos, logo a seguir, presume-se que as melhores respostas possam e certamente devam ser encontradas a partir da própria obra completa heideggeriana.

Nessa perspectiva, embora muitas obras de Heidegger tivessem sido publicadas por diferentes editoras alemãs como a Max

Como tradutor e estudioso da obra heideggeriana para a língua espanhola, Jesús Adrián Escudero inventariou náo só o conjunto dos textos, mas todos os cursos dos quais Heidegger participou como estudante universitário, bem como os cursos e seminários que ofereceu aos alunos, sendo possível acompanhar como foi formando seu próprio perfil filosófico e fenomenológico (Escudero, 2010).

Um dos estudos que melhor documenta a trajetória acadêmica de Heidegger é o de Hugo Ott (Martin Heidegger: a caminho da sua biografia), em que o autor, tendo consultado inúmeras fontes, entre outras coisas, informa das várias bolsas de estudo que o jovem Heidegger usufruiu. Todas elas estavam vinculadas, de alguma forma, à Igreja Católica. 
Niemeyer, de Tübingen e a Günther Neske, de Pfullingen, em 1974 - Heidegger ainda estava vivo -, foi iniciada a edição da obra completa (Gesamtausgabe), pela editora Vittorio Klostermann, de Frankfurt. Esta edição foi planejada pelo próprio filósofo e continua sendo acompanhada pelos herdeiros na pessoa de Hermann Heidegger e é supervisionada por Friedrich-Wilhelm von Herrmann. A edição integral ou edição reunida - como também poderia ser chamada - é dividida em quatro seçóes: a) Escritos publicados (Veröffentlicheschriften), volumes 1 ao 16; b) Preleçóes (Vorlesungen), volumes 17 ao 63, seção subdividida, por sua vez, em: preleções de Marburgo (Marburger Vorlesungen), dos anos de 1923-1928, volumes 17 ao 26, preleçóes de Friburgo (Freiburger Vorlesungen), dos anos de 1928-1944, volumes 27 ao 55 e primeiras preleçôes de Friburgo (Frühe Freiburger Vorlesungen), dos anos de 1919-1923, volumes 56/57 ao 63; c) Tratados inéditos (Unveröffentliche Abhandlungen), volumes 64 ao 81; d) Apontamentos e notas (Aufzeichnungen und Hinweise), volumes 82 ao 102 .

Percebe-se facilmente que a obra heideggeriana é um conjunto muito vasto, pois abrange mais de uma centena de volumes. Diante disso, uma pergunta muito simples, mas importante, deve ser colocada a qualquer leitor ou estudioso de sua obra: qual(is) obra(s) $\operatorname{deve}(\mathrm{m})$ ou merece $(\mathrm{m})$ ser investigada(s)? Depende! Depende de muitas e possíveis variáveis, certamente! Mas, sobretudo, de como e o que se quer ler e estudar na e da obra heideggeriana.

A resposta a esta simples indagação é de suma importância, a fim de dar uma orientação segura à reflexão aqui proposta, a saber: "Da filosofia fenomenológica à fenomenologia da religião”. Diante disso, convém apontar, logo de saída, o que nos interessa particularmente. Interessa-nos a segunda seção da obra completa, que contém as preleçóes (Vorlesungen), isto é, os cursos e seminários universitários que Heidegger ofereceu ao longo de sua carreira acadêmica. Ainda assim, porém, convém ter presente que as preleçóes ocupam cerca da metade da obra completa, ou seja, 47 volumes da obra completa. Diante disso, cabe restringir ainda mais o leque de possíveis volumes a serem pesquisados. Neste caso, o foco de nossa atençáo deve 
voltar-se para a terceira parte da segunda seção, a saber, as primeiras preleçóes oferecidas pelo filósofo na Universidade de Friburgo entre os anos de 1919 a 1923, abrangendo especificamente o volume $56 / 57$ ao volume 63 da edição completa ${ }^{8}$.

Não pretendemos enredar aqui em consideraçôes apenas de ordem bibliográfica. Trata-se apenas de apontar, de passagem, a movimentação que acontece na medida em que Heidegger se ocupa do fenômeno religioso. De qualquer modo, conhecer os bastidores em que o filósofo realiza suas investigaçôes só é possível se seguirmos os vestígios deixados por cada um dos textos e se acompanharmos os exercícios fenomenológicos que Heidegger neles realiza. Somente nesse sentido é possível entender e compreender o modo em que Heidegger concebe e elabora uma fenomenologia da religiáo à sua maneira. Assim, no intuito de compreender adequadamente a obra heideggeriana, é necessário que sejamos capazes de acompanhar o caminho trilhado pelo filósofo, isto é, que sejamos capazes de acompanhar o modo como seus textos se inscrevem no âmbito das grandes obras do pensamento contemporâneo. Com efeito, mesmo na leitura e interpretação de textos aparentemente simples, é preciso náo supor demais, sendo mesmo necessário assumir positiva e reflexivamente as pressuposiçóes que carregamos conosco, a fim de podermos permitir-nos também acompanhar e movimentar-nos nos caminhos trilhados pelo filósofo.

Entretanto, na história da publicação, leitura e interpretação da obra heideggeriana, já houve outros momentos e, pelo visto, não tão bem sucedidos ${ }^{9}$. Benedito Nunes, por exemplo, afirma que a primeira

Tendo em vista o interesse pela fenomenologia da religiáo, a partir de Heidegger, o autor do presente artigo participou na traduçáo, respectivamente, do volume 60 (publicado em 2010) e do volume 63 (publicado em 2012), ambos pela editora Vozes, de Petrópolis.

9 Não nos ocuparemos disso aqui, mas cabe mencionar que, sempre de novo, tendem a se reacender polêmicas em torno da pessoa de Heidegger. Isso aconteceu pela ocasiáo da publicaçáo de um livro de Victor Farias (1987) e está novamente a pleno vapor pela publicação, no âmbito da obra completa heideggeriana, dos assim chamados Schwarze Hefte (Cadernos negros) (2014). Todavia, a fim de não cair em polêmicas esterilizantes ou esterilizadoras, o que nos impele e motiva, a nós mesmos, a ler a obra heideggeriana? Parece-me que toda tentativa de salvar ou condenar Heidegger acaba ficando aquém de uma tentativa de pensar, por nós mesmos, o sentido fundamental da filosofia fenomenológica e, claro, não só "qualquer coisa" que possa se qualificar como sendo ou não "heideggeriano". 
geração de estudiosos brasileiros interessados na obra heideggeriana sofreu uma forte influência do existencialismo francês. Segundo ele, "a filosofia de Heidegger era, entre nós, estudada 'sartreanamente', se é que também não fora 'sartreanizada". Por outro lado, reconhece também que "talvez esteja começando hoje uma nova etapa da interpretação da obra de Heidegger”, uma vez que tem aparecido mais intérpretes da obra do que discípulos de Heidegger (Nunes; Campos, 2007, p. 11). Importante perceber que Nunes atribui uma mudança realmente significativa em grande parte à própria publicação da obra completa (Gesamtausgabe) iniciada na década de 70, pela Vittorio Klostermann, contando, na ocasião, com o planejamento e acompanhamento de Heidegger enquanto ele ainda estava vivo ${ }^{10}$. Otto Pöggeler, um dos estudiosos da obra heideggeriana, escreveu certa vez num texto intitulado "Novos caminhos com Heidegger?" (“Neue Wege mit Heidegger?”):

Por fim, à frente da obra completa, Heidegger quis colocar apenas a seguinte epígrafe: 'Caminhos - não obras'. Esta epígrafe não deve ser mal entendida. Há naturalmente, entre os filósofos, alguns em que existe uma ruptura com o que faziam numa período anterior, contribuindo para náo serem reconhecidos em seus escritos tardios. [...] Atualmente, porém, aconteceu uma ruptura em relação ao pensamento de Heidegger e que não poderá ser desfeito. A única prova se a investigaçáo do pensar de Heidegger propriamente continua válido reside no fato de também ele conduzir a um novo relacionamento para com ele. Pois, se a obra completa de Heidegger são apenas caminhos, estarão hoje em dia também em jogo novos caminhos com Heidegger? (Pöggeler, 1982, p. 40-41) ${ }^{11}$.

10 Em Heidegger e o seu século, escreve Jeffrey Andrew Barash: "Esta edição tornou-se muito rapidamente referência obrigatória para a interpretação do pensamento de Heidegger e vai, sem dúvida, contribuir de maneira significativa para a sua recepção no futuro" (Barash, 1997, p. 136).

11 A tradução desta passagem e do trecho da carta a Richardson são minhas. A primeira foi publicada originalmente em Philosophische Rundschau (cf. Pöggeler, 1982). John D. Caputo, no livro Desmistificando Heidegger, escreve: "Pöggeler considera que Heidegger tem tendência para levar a cabo uma transformação radical 'mais ou menos de cinco em cinco anos'; Martin Heidegger's Path of Thought, p. 280" (cf. Caputo, 1998, p. 66, nota 1). Penso que deveríamos sempre levar a sério a posiçāo do próprio Heidegger numa carta a Richardson, datada de primeiro de abril de 1962, publicada como prólogo em Heidegger: Da fenomenologia ao pensamento (Heidegger: Through Phenomenology to Thought): "A distinçáo que o senhor faz entre 'Heidegger I' e 'Heidegger II' só se justifica desde que se tenha sempre em mente que somente a partir do que é pensado como I pode concordar com o que se deve pensar como II. Pois o I só é possível se está presente no 


\section{Da filosofia fenomenológica à fenomenologia da religião}

No intuito de entender a mudança de Heidegger da filosofia fenomenológica à fenomenologia da religião, é conveniente que tenhamos presente - embora de passagem apenas - o contexto teórico em que se encontravam Husserl e Heidegger durante os anos da Primeira Guerra Mundial e, sobretudo, os anos que se seguiram até que - sob a indicação e recomendação insistente do próprio Husserl ${ }^{12}$ - Heidegger passa a atuar como professor na Universidade de Marburgo, de 1923 a 1928. O fato é que, mesmo estando ainda em Friburgo e, sobretudo, pela publicação póstuma das preleçóes e seminários oferecidos por Heidegger naqueles anos, ainda seria possível dizer que "a fenomenologia" eram apenas Husserl e Heidegger, conforme o mestre pretendia? De fato, por mais nobre e elevado que fosse o empenho de Heidegger na perspectiva de Husserl, hoje em dia não seria muito precipitado concluir apenas isso?

Inicialmente, temos de considerar que se trata de um período em que o próprio Husserl procedeu a uma revisão completa de sua obra principal (cf. Heidegger, 2009, p. 88) - sobretudo das Investigaçóes lógicas -, solicitando para isso a colaboração de Adolf Reinach (1883-1917). Além disso, em 1912, Reinach, juntamente

II. Contudo, qualquer fórmula continua sendo equivocada. A multiplicidade de termos como viragem, esquecimento e destino diz respeito ao complexo temático, em si mesmo multiforme, de ser e tempo, complexo temático que tais termos procuram exprimir. Somente um pensamento multiforme alcança um dizer correspondente à coisa tematizada naquele complexo temático. Este pensamento multiforme não exige uma linguagem nova, mas uma mudança da relação com a essência do antigo."

12 Numa carta a Karl Jaspers, de 19 de novembro de 1922, Heidegger informa: "Quanto regressei a Friburgo, Husserl esperava-me com a notícia de que tinham conhecimento de minhas preleçôes sobre Aristóteles na Universidade de Marburgo e que Natorp desejava receber detalhes concretos sobre os trabalhos que tinha planejado. Em seguida, pus-me a trabalhar por três semanas e redigi uma 'Introdução', da qual enviei respectivamente um exemplar de sessenta páginas para Marburgo e Göttingen por meio de Husserl" (Heidegger e Jaspers, 1992, p. 33-34). A "Introduçăo" a que Heidegger se refere nesta carta, também conhecida hoje em dia como Informe Natorp, foi publicado pela primeira vez em Dilthey-Jahrbuch für Philosophie und Geschichte der Geisterwissenschaften, volume 6, 1989, p. 237-269. Cf. tradução do texto e comentários esclarecedores de Jesús Adrián Escudero (cf. Heidegger, 2002), bem como excelente livro de Carmen Segura Peraita (2002). 
com Moritz Geiger e Alexander Pfänder, haviam ajudado a fundar o famoso Anuário de filosofia e investigação fenomenológica, tendo Husserl como editor principal. De fato, Heidegger mesmo reconhece - num pequeno texto de 1963, já citado - o que este Anuário significou enquanto veículo de divulgaçáo, sendo mesmo sinônimo de fenomenologia:

Então, o ano de 1913 trouxe uma resposta. Na Editora 'Max Niemeyer' começou a ser publicado o Anuário de fllosofia e investigação fenomenológica editado por Husserl. O primeiro volume é inaugurado com o tratado de Husserl que já manifesta, no título, o elemento caracterizador e o alcance da fenomenologia: Ideias a propósito de uma fenomenologia pura e de uma filosofia fenomenológica.

A 'fenomenologia pura' é a 'ciência básica' da filosofia por ela marcada. 'Pura' significa: 'fenomenologia transcendental'. 'Transcendental' é a 'subjetividade' do sujeito que conhece, age e valora. Ambos os títulos 'subjetividade' e 'transcendental' indicam que a 'fenomenologia' se encaminhava, consciente e decididamente, na esteira da tradição da filosofia moderna; fazia-o, não há dúvida, de tal maneira, que a 'subjetividade transcendental' atinge, através da fenomenologia, uma possibilidade de determinação mais originária e universal. A fenomenologia retém as 'vivências conscientes' como área temática; mas, já agora no âmbito da pesquisa da estrutura dos atos vivenciados, sistematicamente projetada e garantida, e isto conjugado à pesquisa dos objetos vivenciados nos atos, sob o ponto de vista de sua objetividade (Heidegger, 2009, p. 87-88).

Entretanto, ao lado do fato da importância na divulgação de textos fenomenológicos, não só de Husserl e Heidegger, mas também de Max Scheler, Edith Stein, Eugen Fink e muitos outros do círculo fenomenológico, de fato, segundo o próprio Heidegger naturalmente olhando em retrospectiva em 1963! - o Anuário trazia outras consequências. Para tais possíveis consequências, gostaríamos de apontar, tomando como referência a citação acima. Se, de um lado, Heidegger reconhece e se mantém na esteira dos temas e preocupaçóes husserlianas, que, aliás, haviam sido despertados nele pelas Investigaçôes lógicas e radicalizadas ainda mais em A filosofia como ciência de rigor (1911), algo realmente importante acontece na medida em que, a partir de 1916, com a mudança de Husserl para a 
Universidade de Friburgo, estabeleceu-se um círculo não formal de fenomenólogos e Heidegger, finalmente, passaria a ter um contato direto com o pai da fenomenologia; por outro lado, e aqui as tarefas das pesquisas atuais da obra heideggeriana certamente encontramse ainda incipientes e, por isso, talvez sejam muito relevantes nos próximos anos, em que Heidegger distingue-se de Husserl em temas como "tempo puro", "fenomenologia pura", "fenomenologia transcendental", "vivências conscientes", por exemplo? Não é necessário ir muito longe para perceber que diferenças fundamentais irão se acentuando cada vez mais ao longo dos anos de 1916 a 1927. Naturalmente, não é possível dizer que Heidegger se afasta totalmente de Husserl. A dedicatória, além de outras referências explícitas em Ser e tempo ao mestre, são a prova do reconhecimento e da dívida de Heidegger com Husserl ${ }^{13}$.

Diante disso e dentro das condiçóes e limites que a presente reflexão pode oferecer, nosso propósito consiste em evidenciar que na obra Fenomenologia da vida religiosa, certamente, encontramse algumas preocupaçóes fenomenológicas de Heidegger muito peculiares. Contudo, antes de dar prosseguimento nessa direção, é importante dizer que durante décadas os nomes de Husserl e de Heidegger sequer eram referenciados no que diz respeito à fenomenologia da religião.

A fenomenóloga italiana Angela Ales Bello, estudiosa da obra de Husserl, escreve: "A propósito, eu quis submeter à crítica um preconceito segundo o qual Husserl não se teria interessado por questóes filosóficas concernentes tanto ao problema de Deus quanto à temática da teologia e da religião" (Ales Bello, 1998, p. 97). Mais adiante, a mesma autora também registra: "Husserl certamente

As investigaçóes de Husserl fizeram Heidegger despertar para o problema do tempo de uma maneira toda nova. Uma prova disso está na "Nota prévia do editor", assinada por Heidegger, do ano de 1928. Nessa nota lê-se: "Decisiva é aqui a explicitação do caráter intencional da consciência do tempo e a crescente clarificação principial da intencionalidade em geral. [...] Ainda hoje, esta expressão não é um santo-e-senha, mas sim o título de um problema central (cf. Edmund Husserl, Liçôes para uma fenomenologia da consciência interna do tempo, Lisboa, Imprensa Nacional da Moeda, 1994, p. 25). Todavia, há uma distância enorme entre a compreensão do tempo das "preleçóes ministradas por Husserl durante os anos de 1893 a 1917" e Ser e tempo, obra publicada em 1927. 
não era um estudioso conhecido pelas suas investigaçóes sobre as culturas e sobre as religióes. [...] Por isso, desperta uma certa surpresa o fato de que van der Leeuw tenha intuído as potencialidades da fenomenologia nesta direção" (Ales Bello, 1998, p. 107). Com efeito, em diferentes estudos a fenomenóloga italiana trouxe à tona o interesse de Husserl pelo fenômeno religioso a partir de manuscritos inéditos. No entanto, era sabido também que Husserl mesmo incentivara que vários de seus alunos - entre eles, A. Reinach, E. Stein e o próprio Heidegger - se ocupassem com temáticas religiosas.

Quanto ao interesse de Heidegger por textos religiosos, durante os primeiros anos em Friburgo, na perspectiva da fenomenologia da religião, já eram conhecidos, há bastante tempo, e por duas razóes: a) havia textos publicados, desde os primeiros anos como estudante em Friburgo, nos quais tal interesse estava manifesto no próprio título e desdobramentos ${ }^{14}$; b) mais conhecidas, embora não publicadas em vida, porém, são as anotaçóes e preleçóes dos primeiros anos como professor em Friburgo ${ }^{15}$.

Além dos textos de Heidegger sobre fenomenologia da religião dos primeiros anos como professor não estarem publicados oficialmente antes de 1995, convém ter presente que aproximadamente uma década após Heidegger ter se ocupado com fenomenologia da religião nas preleçóes em Friburgo, Gerardus van der Leeuw (18901950) publicou uma obra sistemática e abrangente onde, ao lado de outros estudiosos da religião, os nomes de Husserl e Heidegger são exemplarmente citados quando se trata de compreender o método

14 É o caso, por exemplo, de A doutrina das categorias e da significação de Duns Escoto, de 1915 e publicado em 1916. Outras referências, porém, podem ser muito sutis e até passar despercebidas a um leitor desatento, sendo um exemplo a epígrafe a Mestre Eckhart: "Tempo é o que se altera e diversifica, a eternidade se mantém simples" ("Zeit ist das, was sich wandelt und mannigfaltigt, Ewigkeit hält sich einfach). Cf. O conceito de tempo na ciência histórica (Der Zeitbegriff in der Geschichtswissenschaft), aula de habilitaçáo proferida no dia 27 de julho de 1915, em Friburgo, e publicada numa revista no ano seguinte.

15 Desde o início dos anos 60, era possível tomar conhecimento parcial das preleções de Heidegger sobre fenomenologia da religiāo em Friburgo, através de comentadores, como é o caso de $A$ via do pensamento de Martin Heidegger (Der Denkweg Martin Heideggers), de Otto Pöggeler. Interessante observar que, um dos livros que se tornou referencial no Brasil em termos de uma introdução aos estudos da obra heideggeriana, $A$ gênese da ontologia fundamental, de João Augusto A. Amazonas Mac Dowell, publicado pela Herder de São Paulo em 1970, tenha se baseado consideravelmente no livro de Pöggeler, cuja primeira publicaçáo remonta ao início dos anos 60 . 
fenomenológico (van der Leeuw, 1977) ${ }^{16}$. Provavelmente, no início dos anos 30, Heidegger mesmo ainda não cogitasse que suas preleçôes algum dia viriam a público. Sobre van der Leeuw escreve Tommy Akira Goto num trabalho de pós-graduação em Ciências da Religião pela Universidade Metodista de São Paulo:

O primeiro sistematizador oficial da fenomenologia no campo religioso foi o historiador das religióes Gerardus van der Leeuw (1909-1950), cuja obra Fenomenologia da religião (Phänomenologie der Religion) foi publicada em 1933. Essa obra abriu, decididamente, o caminho para que a fenomenologia da religião seguisse na direção de se constituir uma 'ciência' no estudo da religiáo e do sagrado. A proposta de van de Leeuw foi transformar a fenomenologia da religião numa 'ciência' primeira, diferenciando-a de outras ciências (Goto, 2011, p. 63).

A menção aqui ao volumoso livro de van der Leeuw não deve ser visto sem maiores consideraçôes, na medida em que suas diversas versóes e, principalmente, pelo fato de ter sido traduzido sucessivamente para diversas línguas, tornou-se sinônimo de "fenomenologia da religião"17. Hans-Jürgen Greschat registra que, na esteira de van der Leeuw, foram publicados dois outros "clássicos" de fenomenologia da religião: Geo Widengren (1907-1996), professor sueco de Uppsala, publica Fenomenologia da religião (Religionsphänomenologie, tradução alemã de 1969), livro que, ao que tudo indica, teve uma primeira versão já nos anos 40; além disso, em 1961, Friedrich Heiler (1892-1967), publica Formas de manifestação e essência da religiāo (Erscheinungsformen und

16 Algumas particularidades da obra Fenomenologia da religiāo de Gerardus van der Leeuw: a primeira versão, publicada na Holanda em 1924, foi traduzida para o alemão no ano seguinte, contendo entáo apenas 33 parágrafos; a versão clássica, de 1933, ainda não continha os parágrafos 79 a 102, sendo acrescentados na edição póstuma de 1956; no prefácio, à ediçâo dos anos 30, o autor agradece pela participaçáo e contribuiçáo de Rudolf Bultmann, bem como menciona o filósofo Karl Jaspers.

17 Em 1925, Friedrich Heiler, então professor na Universidade de Marburgo, traduziu e publicou Introdução à fenomenologia da religiāo (Einfürung in die Phänomenologie der Religion, Munique, Ernst Reinhardt) para a língua alemã. Heiler, proveniente de uma família católica, tornou-se professor na universidade de Munique, de onde, em 1920, mudou-se para faculdade de teologia da Universidade de Marburgo, tornando-se professor em 1922. A língua inglesa conheceu uma tradução da obra já em 1938: Religion in essence and manifestation: a study in phenomenology, realizada por J. E. Turner. Durante os anos 40, foi preparada uma "tradução" (com a colaboração do autor) para o francês, por Jacques Marty: La religion dans son essence et ses manifestations, phénoménologie de la religion, publicada em 1948, em Paris, pela editora Payot. Van der Leeuw viria a falecer em 1950. 
Wesen der Religion) (cf. Greschat, 2006, p. 135-142). Apesar de Greschat não mencionar, há ao menos outro livro digno de nota: Introdução à fenomenologia da religião, de Juan Martín Velasco, publicada pela primeira vez em 1973 e que, em 2006, encontrava-se na sétima edição revista e ampliada (Velasco, 2006). Feitas estas mençôes a autores e obras que certamente se tornaram referenciais no que diz repeito à fenomenologia da religião, vejamos a conclusão a que chega Greschat:

Não há muita diferença entre a primeira, a segunda e a terceira Fenomenologia da religião. Quem escreveu uma nova não tinha a intenção de imitar seus antecessores, mas optou por uma maneira de apresentação e uma organização dos parágrafos que se destacam das anteriores. Do ponto de vista do conteúdo, porém, é muito pouco o que distingue os livros (Greschat, 2006, p. 141).

Entretanto, esta conclusão requer que façamos algumas observaçóes, no sentido de retomarmos a linha condutora da temática desenvolvida no presente artigo, a saber: em que consiste propriamente a fenomenologia da religião em e para Heidegger? De fato, levando-se minimamente em conta os livros dos fenomenólogos da religiáo comparados por Greschat, percebe-se facilmente que o conteúdo das preleçóes de Heidegger do primeiro período em Friburgo se distingue da sistematicidade dos autores citados. É bem verdade: Greschat sequer cita Heidegger, ao menos não no sentido que pudesse ter alguma relevância ou algum peso ao lado de van der Leeuw, Heiler e Widengren. Contudo, antes destes "clássicos" da fenomenologia da religião, não houve outros fenomenólogos que tivessem se ocupado com o "fenômeno religioso"? De fato, ao lado de Heidegger, já tínhamos mencionado outros nomes que, estando igualmente próximos de Husserl, acabaram por escrever obras significativas, sendo - também elas! - muito distintas fenomenologicamente entre si e das ideias desenvolvidas por Heidegger, seja pelo conteúdo seja pelo modo como assimilam e desenvolvem a fenomenologia enquanto método de investigaçáo ${ }^{18}$.

18 Pela contemporaneidade com as preleçōes de Heidegger na primeira fase como professor em Friburgo, convém destacar os trabalhos, segundo as ediçóes espanholas levadas a efeito pela Encuentro, de Madri, ambas de 2007: Adolf Reinach, Anotaciones sobre filosofia de la religión 
Contudo, no que diz respeito a Heidegger, encontramse publicados atualmente vários volumes da obra completa que evidenciam, direta e indiretamente, uma preocupação pela interpretação de textos religiosos e na compreensão de fenômenos religiosos. Entretanto, convém já fazer uma advertência em forma de questionamento: onde começa e onde termina o interesse de Heidegger pelo fenômeno estritamente religioso em sentido próprio?

Apoiando-nos num comentário de John Caputo, a propósito da "dificuldade da vida e a hermenêutica da faticidade", onde está em jogo a própria "luta (Kamp) de Heidegger", podemos ler:

Uma coisa que emerge claramente da leitura das primeiras conferências de Friburgo (1919/1923) é o fato de Heidegger ter sido, desde o início, um filósofo revolucionário, propenso a efetuar uma renovaçáo radical da existência e do pensamento, a reconduzir a vida às suas fontes e recursos mais profundos. Sempre encarou como sua tarefa apontar o caminho na direçấo de uma nova ordem, tendo constantemente por objetivo uma espécie de 'outro início', de um tipo ou de outro. Heidegger era um 'radical' que procurava uma renovação radical, um radical cuja radicalidade assumiu (no mínimo) formas diferentes em momentos diferentes, passando por diversas 'viragens' (que cada dia que passa são mais difíceis de contar (Caputo, 1998, p. 66).

Do conjunto de volumes da obra completa e embora já tenhamos apontado para o fato de que o fenômeno religioso ocupa um lugar especial no período em que Heidegger foi professor em Friburgo, nossa atenção deve voltar-se particularmente para o volume 60 da obra completa: Fenomenologia da vida religiosa (Phänomenologie des

(presume-se serem anotaçóes feitas pelo autor, na frente de batalha, durante a Primeira Guerra Mundial, onde veio a falecer) e Max Scheler, De lo eterno en el hombre (publicado em 1921). Além disso, devemos ter presente que, entre as últimas décadas do século XIX e início do século $\mathrm{XX}$, produziu-se grande quantidade de estudos relacionados à filosofia da religiâo. Duas escolas de pensamento fortemente influenciaram os estudos daquela época: o neokantismo e o hegelianismo, como também o historicismo. Alguns autores que marcaram o jovem Heidegger: E. Husserl, F. Brentano, D. Escoto, M. Lutero, W. Dilthey, S. Kierkegaard, Mestre Eckhart, por exemplo. Contudo, em textos seus dessa época são citados também nomes como Troeltsch, Droysen, Rickert, Ranke, Windelband, Simmel e Misch. De fato, há várias obras importantes sobre o fenômeno religioso dessa época, entre as quais convém destacar: $O$ sagrado: delineamentos para a filosofia da religiäo (1902), de Wilhelm Windelband; A religiäo dentro dos limites da bumanidade (1908), de Paul Natorp; O conceito de religiäo no sistema da filosofia (1913), de Hermann Cohen; O sagrado: os aspectos irracionais na noção do divino e sua relação com o racional (1917), de Rudolf Otto; Comentário à Carta aos romanos (1919). 
religiösen Lebens) (Heidegger, 2010). Neste volume, publicado pela primeira vez em meados de 1995 , estáo reunidas preleçóes em que se pode falar propriamente que Heidegger tenha buscado forjar e estabelecer uma peculiar fenomenologia da religião.

Importante observar que os volumes contendo as preleçóes da atuação do jovem professor Heidegger nos primeiros anos em Friburgo, nem sempre são muito sistemáticos, seja porque nem Heidegger os concebeu assim seja porque em parte o conteúdo editado provém, também, de alunos que assistiram às preleçóes, tendo tomado nota do conteúdo que tinham ouvido e acompanhado as exposiçóes e reflexôes na sala de aula. Além disso, alguns dos volumes reúnem às vezes mais de um texto. É mesmo o caso do volume 60! Este volume reúne os seguintes textos: "1. Introdução à fenomenologia da religiáo" (preleçôes do semestre de inverno de 1920/21); "2. Agostinho e o neoplatonismo" (preleções do semestre de verão de 1921); “3. Os fundamentos filosóficos da mística medieval" (que contitui um conjunto de anotaçóes para um curso que acabou não sendo oferecido por causa da guerra) ${ }^{19}$.

A estrutura da primeira parte deste volume contém: "Introdução à fenomenologia da religiáo", sendo as primeiras preleçóes friburguenses do semestre de inverno de 1920/21. Esta parte reúne, por sua vez, uma subdivisão: "Primeira parte: Introdução metodológica: filosofia, experiência fática da vida e fenomenologia da religiāo" (Heidegger, 2001, p. 9-60) e "Segunda parte: Explicação fenomenológica de fenômenos religiosos concretos tomando por base as epístolas paulinas" (Heidegger, 2001, p. 61112). Além disso, há ainda um "Anexo: Apontamentos e esboços para a preleção" (Heidegger, 2001, p. 113-139), texto estritamente relacionado às duas partes, tendo em vista que são anotaçóes em que passagens particularmente importante são explicadas e aprofundadas por Heidegger.

19 O volume 60 foi publicado pela Vittorio Klostermann, de Frankfurt, em 1995. Um trabalho primoroso, publicado recentemente no Brasil, partindo do conjunto de textos deste volume da obra completa heideggeriana, é de Bento Silva Santos, Fenomenologia e Idade Média, Curitiba, CRV, 2013. 
No posfácio, sobre a edição do texto "Introdução à fenomenologia da religião", informam os editores Matthias Jung e Thomas Regehly (Heidgger, 2010, p. 321-324), que o manuscrito da preleção infelizmente foi extraviado. Porém, conservaram-se cinco anotaçóes manuscritas de alunos que permitiram reconstruir de forma aproximada a direção do pensamento e o teor literal da preleção. Segundo os editores, três dessas anotaçóes (de Oskar Becker, Helene Weiss e Franz-Josef Brecht) encontram-se no Arquivo de Literatura Alemã de Marbach e outros dois (de Franz Neumann e Fritz Kaufmann) estão guardados no Arquivo Husserl de Lovaina. A estas anotaçóes foram acrescentadas apontamentos manuscritos do próprio Heidegger ao contexto da preleção. São folhas soltas de uma pasta conservada atualmente no Arquivo de Marbach (Heidgger, 2010, p. 323).

Em que contexto acadêmico são oferecidas estas preleçóes? A proximidade pessoal e temática de Heidegger com Husserl, desde 1918, contribui decisivamente para que suas investigaçóes tivessem a marca de uma fenomenologia da religião, cuja elaboração detalhada Husserl havia encarregado seu assistente. Contudo, Heidegger já trabalhava numa concepção própria da fenomenologia, partindo do conceito da experiência fática da vida. De fato, a discussáo continuada com a tradição cristã representa o contexto dentro do qual Heidegger desenvolverá a hermenêutica da faticidade (Heidegger, 2010, p. 324).

De fato, as investigaçóes realizadas por Heidegger depois de 1915 revelam que se afasta gradativamente das diversas vertentes fenomenológicas correntes naqueles anos. Enquanto Husserl e Scheler, por exemplo, usavam expressôes como "vida humana" (menschlische Leben), "vivência" (Erlebnis) ou "mundo da vivência" (Lebenswelt) para descrever a experiência originária da vida humana, Heidegger passa a utilizar expressóes como hermenêutica da faticidade e, a partir disso, realiza análises totalmente novas no campo da fenomenologia. Isso fica mais evidente em expressóes novas que, pouco a pouco, começam a aparecer em suas reflexóes, entre as quais: "faticidade" (Faktizität), "mundo próprio" (Selbstwelt), "mundo circundante" (Umwelt), "mundo compartilhado" (Mitwelt), 
"circunvisão" (Umsicht), "ser-no-mundo" (In-der-Welt-sein), dentre muitas outras correlacionadas. Nesse sentido, as reflexôes e análises do volume 63 (Heidegger, 2012), tendo por título Ontologia (hermenêutica da faticidade), do semestre de verão de 1923, são uma evidência das preocupaçóes filosóficas heideggerianas naqueles anos (Capelle-Dumont, 2012, p. 218-227).

A mudança fundamental, contudo, não reside apenas na mudança e no emprego de novos conceitos filosóficos. Temos de perguntar-nos: qual o sentido da mudança e do emprego dos conceitos nestas análises fenomenológicas? Ao propor e fazer uma hermenêutica da faticidade, Heidegger está preocupado em garantir e salvaguardar a unidade estrutural do fenômeno do mundo do ser-aí humano. Nosso objetivo, portanto, consiste em olhar para dentro dos bastidores das primeiras investigaçóes fenomenológicas realizadas por Heidegger enquanto era ainda um jovem professor e, provavelmente, nem muito conhecido ainda, sobretudo ainda não fora da Alemanha.

Tendo presente este contexto acadêmico e filosófico alemão, é possível aproximar-nos propriamente do modo como Heidegger realiza seus primeiros exercícios fenomenológicos em vista de uma peculiar fenomenologia da religiáo. Assim, poderíamos perguntar: ao ler e interpretar textos de Paulo, Agostinho e Eckhart, o jovem Heidegger está interessado em quê? E, para o que nos interessa particularmente no presente artigo, qual o objeto e a tarefa que ele se impóe ao ler e interpretar as epístolas paulinas, já que são estas que ocupam Heidegger na "Introduçáo à fenomenologia da religiáo" durante as releçóes friburguenses do semestre de inverno de 1920/21 (Heidegger, 2010, p. 61-112)?

Embora o desenvolvimento do método fenomenológico heideggeriano esteja presente e atravesse o conjunto de textos reunidos no volume 60, importante dar atenção para um dos capítulos da "Parte II: Explicação fenomenológica de fenômenos religiosos concretos tomando por base as epístolas paulinas". O "Capítulo 2: Tarefa e objetualidade da filosofia da religiáo", é desenvolvido mediante seis parágrafos, como segue: $\$ 17$. A 
compreensão fenomenológica; $\$ 18$. A fenomenologia da religião e a história da religião; $\mathbb{\$} 19$. As determinaçôes fundamentais da religiosidade cristá originária; $\$ 20$. O fenômeno da proclamação; $\$$ 21. Preconceitos da consideração; $\$ 22$. O esquema da explicação fenomenológica. Pois bem, pela menção explícita feita à "fenomenologia da religiáo" no título do $\$ 18$, vejamos o que diz Heidegger:

É possível utilizar o material da filosofia da religiáo para a fenomenologia? De que modo a história da religiáo mesma em geral é adequada em sua objetualidade? Seria possível dizer que se a história da religião explica a religiosidade a partir do mundo religioso circundante, como a partir da história da época, como se lhe poderia censurar que náo lhe é possível alcançar sua objetualidade? Ela apenas interpreta, enquanto ciência objetiva, livre de prejuízos e opiniōes prévias, em virtude do material de sentido que as fontes contemporâneas alegam, com independência de todas as tendências do presente. Esta argumentação, contudo, tem uma aparência de justificação. Por um lado, é necessário dar razão até certo ponto; por outro lado, porém, deve-se contrapor: toda objetividade histórico-científica e a compreensão do históricoobjetiva náo garantem nada enquanto tudo não for esclarecido no que diz respeito ao preconceito condutor (leitenden Vorgriff) (Heidegger, 2010, p. 69-70).

Seja pelo conjunto dos seis parágrafos sob o capítulo 2, seja pelo teor específico e o que é acentuado por Heidegger na passagem citada, imprescindível fazermos algumas considerações no sentido de resguardar o que, afinal, o filósofo de Messkirch entende propriamente por "fenomenologia da religiáo". Expliquemos: a) o plano teórico e científico de fundo, a princípio, dá motivo para que facilmente nos desviemos das intençóes de Heidegger, ou seja, ele mesmo contrapóe: "toda objetividade histórico-científica e a compreensão do histórico-objetiva não garantem nada enquanto tudo não for esclarecido no que diz respeito ao preconceito condutor". Podese deduzir que há, de fato, uma discussão sobre o que se entende por "religião" e "religiosidade", mas que, provavelmente, tanto a filosofia em voga como o conjunto das ciências a se ocuparem com o "fenômeno religioso", náo sejam capazes de "ir às coisas mesmas" 
(zu den Sachen selbst); se isso procede, então: b) é possível que a advertência (contraposição) seja mesmo um aceno ou indicação ao que realmente é fundamental para Heidegger e, neste caso, também haveria uma distinção nítida entre "filosofia da religião" e "fenomenologia da religião", ou seja, embora no conjuntos das preleçóes seja tão frequente a primeira como a segunda expressão, não há como negar que as inteçóes heideggerianas são claramente fenomenológicas.

Com efeito, Heidegger requer que tudo seja "esclarecido no que diz respeito ao preconceito condutor (leitenden Vorgriff)". Ora, perguntar pelo que é pressuposto fundamentalmente enquanto fio condutor das ciências positivas implica em questionar ou advogar pela cientificidade delas. Nestes termos, poderíamos admitir uma "ciência prévia" (Vorwissenschaft)? Ciência prévia seria, então, sinônimo de ciência ontológica ou simplesmente ontologia. Portanto, a preocupação de Heidegger, realmente, não é ôntica, na medida em que uma ciência prévia deve ser condiçáo de possibilidade de toda e qualquer investigação ôntica ou científica e é isso que pretende Heidegger.

Mas isso ainda não é tudo. Afinal, qual seria memso a condição de possibilidade de acesso aos fenômenos concretos investigados nas preleçóes de Friburgo e nas quais seria possível arrostar uma "fenomenologia da religiáo" propriamente heideggeriana? Para responder a esta pergunta, náo devemos perder de vista o teor do capítulo que abre e antecede o capítulo 2, isto é, o "Capítulo 1: Interpretação fenomenológica da Epístola aos Gálatas” (Heidegger, 2010, p. 61-67). Com efeito, a "Parte II" do curso "Introdução à fenomenologia da religião" não leva por título "Explicação fenomenológica de fenômenos religiosos concretos tomando por base as epístolas paulinas"? Sendo mais específicos ainda, vale a pena prestar atenção ao início do "\$14. Introdução", sendo o primeiro parágrafo do "Capítulo 1":

No que segue, não temos a intenção de oferecer nem uma interpretação dogmática ou teológico-exegética, nem tampouco um estudo histórico ou uma meditação religiosa, mas oferecer tão-somente uma introdução 
à compreensão fenomenológica (eine Anleitung zum phänomenologischen Verstehen). O peculiar da compreensão fenomenológico-religiosa é a obtenção de uma compreensão prévia (Vorverständnis) para uma via originária de acesso (ursprünglechen Weg des Zugangs). Nessa direção se fará necessário elaborar e interpretar o método da história das religiôes de tal modo que possa ser comprovada criticamente. $\mathrm{O}$ método teológico está fora de nossas consideraçôes. É pela compreensão fenomenológica que se abre um novo caminho para a teologia. $\mathrm{O}$ indício formal (formale Anzeige) renuncia à compreensão última que só pode dar-se numa vivência religiosa genuína; tem a intenção somente de inaugurar e abrir o acesso ao Novo Testamento (Heidegger, 2010, p. 61).

Por um lado, esta passagem é autoexplicativa na medida em que nos esclarece as motivaçóes do jovem Heidegger em vista de uma fenomenologia da religião. Muito brevemente: fica claro que, embora esteja em jogo uma interpretação da Espístola aos Gálatas, de Paulo, o foco não é de ordem dogmática, teológica-exegética, histórica, meditativa! O fenomenolólogo insiste: "O peculiar da compreensão fenomenológico-religiosa é a obtenção de uma compreensão prévia (Vorverständnis) para uma via originária de acesso (ursprünglechen Weg des Zugangs)". Por outro lado, fica por esclarecer devidamente o que se entende ali por "indício formal". Para isso, é pertinente dar atenção ao " $\$ 13$. O 'indício formal', sendo um dos parágrafos do último capítilo da "Parte I", a saber: "Capítulo 4: A formalização e o indício formal”:

O que é a fenomenologia? O que é o fenômeno? Isso só pode ser anunciado formalmente aqui. - Toda experiência - como o experimentar enquanto o que experimenta - pode 'ser assumido no fenômeno', isto é, pode tornar-se questionável:

1) Pelo 'quê'originário (ursprünglichen 'Was'), que é experimentado nele (conteúdo) (Gehalt);

2) Pelo 'como' originário (ursprünglichen 'Wie), em que é experimentado (referência) (Bezug);

3) Pelo 'como' originário (ursprünglichen 'Wie'), no qual o sentido referencial é realizado (realização) (Vollzug).

Essas três direçôes de sentido (sentido de conteúdo, de referência e de realização) não estão colocadas simplesmente umas ao lado das outras. 'Fenômeno' é uma totalidade de sentido (Sinnganzheit) segundo essas três direçôes. 'A fenomenologia' é a explicação desta totalidade de 
sentido, fornece o 'logos' dos fenômenos, 'logos' em sentido de 'verbum internum' (não no sentido de logicização) (Heidegger, 2010, p. 58).

Vê-se claramente por esta passagem que a "fenomenologia da religião", segundo Heidegger, deve colocar o acento "totalidade de sentido" (Sinnganzheit) da religiáo. Seu interesse volta-se para a experiência da religiosidade originária. Contudo, como e até que ponto é isso possível fenomenologicamente? Enfim, qual o propósito de Heidegger propriamente dito? Desse modo, em que sentido pode-se falar em "fenomenologia da religiáo" a partir de Heidegger? Assim, na intenção de determinar o melhor possível o objeto e a tarefa ou método da fenomenologia da religião, apresentaremos, a seguir, algumas indicaçóes preliminares que poderáo orientar a leitura e interpretação das preleçôes friburguenses reunidas sob o título geral Fenomenologia da vida religiosa:

a) Quanto ao objeto da fenomenologia da religião: trata-se de voltar à experiência cristã originária e de compreender o problema da explicação religiosa; a compreensão fenomenológica deve fazer a experiência da objetualidade em sua originalidade; a fenomenologia deve ter continuamente em vista o problema do conceito prévio relacionado à história; a religiosidade cristã consiste na experiência cristã de vida originária e é, enquanto tal, ela mesma; a experiência fática da vida é histórica. Enfim, a religiosidade cristã ensina e vive a temporalidade enquanto tal.

b) Quanto à tarefa ou método da fenomenologia da religião: segundo Heidegger, a compreensão fenomenológica está situada, fundamental e totalmente, fora da oposição entre racional e irracional, entre sujeito e objeto; não se deve emprestar qualquer teoria ou modo de interpretação para a determinação do objeto investigado e da tarefa a ser empreendida; a proclamaçáo de Paulo, enquanto fenômeno religioso, deve ser analisada em todas as direçóes fenomenológicas de sentido; o fenômeno da proclamação é uma referência vital imediata do mundo próprio (Selbstwelt) do apóstolo Paulo em relação ao mundo circundante (Umwelt) e do mundo compartilhado (Mitwelt) com a comunidade na qual se encontra e da qual suas epístolas provêm. Este é, portanto, um fenômeno central. 
Diante disso, podem ser colocadas ainda questóes: Quem proclama? Como proclama? Que é proclamado? Heidegger irá enfatizar o "como" (Wie) da proclamação (Verkündigung) (Heidegger, 2010, p. 72-73). Nesse sentido, a realização da vida é decisiva, ou seja, como a mensagem proclamada é experimentada e vivida. Está em jogo, portanto, analisar o conteúdo proclamado, sua temática e seu aparato conceptual. A compreensão fenomenológica sempre tem em vista um fenômeno bem determinado e, nesse sentido, parte de um ponto inicial (preconceito). A compreensão fenomenológica é determinada pelo fato de que, na proclamação paulina, o espectador deve ser levado em conta. Este se realiza, ou seja, faz a experiência da mensagem proclamada e isso o atinge de modo direto, concreto e imediato em sua situação vital.

Diante disso, na perspectiva da "fenomenologia da religião", segundo Heidegger, deve-se uma postura à altura da religiosidade cristá originária, na medida em que ela: 1) encontra-se na experiência fática da vida enquanto tal, particularmente Paulo; 2) a experiência fática da vida é histórica, ou seja, ela vive o tempo de fato ("viver" entendido como verbo transitivo) e, neste sentido, a proclamação apostólica é uma característica demasiadamente ampla do fenômeno. Assim, as epístolas paulinas são, enquanto fontes, mais diretas e imediatas do que os Evangelhos canônicos escritos posteriormente. Além disso, não se deve isolar o caráter epistolar nem introduzir meras questóes de estilo literário ao problema. O estilo epistolar mesmo é expressão do escritor e de sua intenção. Embora as epístolas paulinas estejam cronologicamente tâo próximas umas das outras, são muito diversas entre si. Por isso, é necessário também livrar-se da divisão meramente esquemática das epístolas. A explicação das epístolas não se restringe a uma sequência diferenciada de atos ou mesmo de algumas notas de apreensão em termos de conteúdo. Só é possível obter uma explicação fenomenológica apropriada a partir do contexto vital concreto do qual as epístolas paulinas surgiram e nos foram transmitidas ao longo dos séculos em sua vitalidade fenomenal genuína. 


\section{Análise fenomenológica da experiência fática da vida}

No intuito de compreender como Heidegger entende por "fenomenologia da religião" é imprescindível acompanhar as análises por ele realizadas da "experiência fática da vida" (faktische Lebenserfahrung), cuja determinação encontra-se emblematicamente formulada na primeira parte da "Introdução à fenomenologia da religião", mais especificamente, no " $\$ 3$. A experiência fática da vida como ponto de partida":

A experiência fática da vida é qualquer coisa totalmente peculiar. Ela torna possível nela mesma o caminho para a filosofia, uma vez que nela se realiza também a virada [Umwendung] ${ }^{20}$ que conduz à filosofia. Esta dificuldade é compreendida através da característica provisória do fenômeno da experiência fática da vida. A experiência da vida é mais do que a mera experiência de tomada de conhecimento. Ela significa a plena colocação ativa e passiva do homem no mundo: vemos a experiência fática da vida apenas segundo a direção do comportamento que experimenta. Assim, definimos o que é experimentado - o vivido - enquanto 'mundo', não como 'objeto'. 'Mundo' é algo no qual se pode viver (num objeto não é possível viver) (Heidegger, 2010, p. 15-16).

Contudo, o que significa "experiência fática da vida"? "Experimentar" não significa "tomar conhecimento", mas o "confrontar-se com" o que é experimentado, o "afirmar-se" das formas experimentadas. Isso possui um significado tanto positivo quanto negativo. O significado do conceito "fático" não significa realidade natural, não significa determinação causal e nem coisa

20 Embora na maior parte das vezes se faça menção à “virada” (Kehre) heideggeriana por volta do fim dos anos 20 e início dos 30, importante náo perder de vista que o afastamento de Heidegger do sistema do catolicismo e o retorno aos textos da tradição cristã originária significou uma primeira "virada" (Umwendung) em sua trajetória filosófica (Inwood, 2002, p. 202-204). A referência marcante desta mudança de direção, quer no pensamento quer em sua vida pessoal, consta numa carta que Heidegger escreveu, no dia 9 de janeiro de 1919, para Engelbert Krebs, padre católico que oficiara seu casamento e professor de teologia na Universidade de Friburgo: "Perspectivas epistemológicas que ultrapassam a teoria do conhecimento histórico tornaram problemático e inaceitável para mim o sistema do catolicismo - mas não a cristandade e a metafísica, embora eu considere a última num novo sentido" (Sheehan, 2000, p. 89). 
concreta. O conceito "fático" não alcança seu significado a partir de determinados pressupostos da teoria do conhecimento, uma vez que deve ser compreendido apenas através e pelo conceito do "histórico" (Heidegger, 2010, p. 32-43).

Segundo Heidegger, o "ponto de partida" (Ausgangspunkt) do "caminho para a filosofia" (Weges zur Philosophie) é a "experiência fática da vida” (faktische Lebenserfhrung) mesma. Nesse sentido, a experiência fática da vida revela algo totalmente peculiar. Ela torna possível, nela mesma, o caminho para a fenomenologia, uma vez que nela se realiza também a virada que conduz à filosofia propriamente dita. Diante disso, qualquer experiência da vida que se faça, é sempre e fundamentalmente mais do que uma experiência como mera tomada de conhecimento disso ou daquilo. Assim, experiência fática da vida significa a plena colocação ativa e passiva do homem no mundo, ou seja, vemos a experiência fática da vida apenas segundo a direção do comportamento que experimenta. Segundo Heidegger, podemos definir o que é experimentado - o vivido - enquanto "mundo", não como "objeto". Pois, como ele mesmo escreve: “Mundo’ é algo no qual se pode viver (num objeto não é possível viver)" (Heidegger, 2010, p. 16).

O mundo pode ser formalmente articulado como mundo circundante (Umwelt), como aquilo que nos vem ao encontro, ao qual pertencem não apenas coisas materiais, mas também objetualidades, ideais, ciências, artes etc. Nesse mundo circundante também está o mundo compartilhado (Mitwelt), isto é, outros homens numa característica fática bem determinada: como estudante, docente, parente, superior etc. - portanto, náo meramente enquanto exemplar do gênero homo sapiens das ciências naturais e assim por diante. Finalmente, aí estou também eu mesmo, ou seja, meu mundo próprio (Selbstwelt), sendo que fenomenologicamente as três dimensôes de mundo estão intimamente relacionadas entre si e são elas mesmas que constituem a experiência fática da vida (Heidegger, 2010, p. 16).

Diante disso, antes de qualquer decreto de que a filosofia seja meramente tomar conhecimento, deve-se tornar evidente 
fenomenologicamente, a partir da experiência fática da vida, o que pertence a todo e qualquer conhecer em sentido ontologicamente originário. A experiência fática da vida não reside totalmente no conteúdo e, por isso, trata-se e evidenciar o "como" (Wie) implícito na experiência fática da vida. Não é pelo conteúdo, mas pelo como que têm lugar todas as mudanças da vida. Por exemplo, no curso da jornada de um dia faticamente vivido, ocupando-se com coisas completamente diferentes é pela atuação fática da vida que surge, segundo Heidegger, de modo náo consciente, o como diferente de seu reagir em cada maneira diferente. Portanto, a experiência fática da vida náo surge de forma alguma em pensamentos, como se não pudesse tornar algo acessível.

O experimentar fático contesta ao mesmo tempo todas as oportunidades da vida. A distinção e uma mudança de acento situam-se totalmente no modo de ser mesmo do ser-aí humano. Essa indiferença funda, portanto, a autossuficiência da experiência fática da vida. Ela se expande sobre tudo, ou seja, distingue também as coisas maiores em sua autossuficiência. Portanto, se atentarmos para a indiferença própria do experimentar fático em todas as faticidades da vida, então, evidencia-se claramente um determinado sentido dominante do mundo circundante, do mundo compartilhado e do mundo próprio, a saber: tudo o que é experimentado na experiência fática da vida carrega o caráter de significância:

No modo de ser da significância (Weise der Bedeutsamkeit), que determina o caráter do experimentar mesmo, eu experimento todas as minhas situaçóes fáticas da vida. Isto se torna claro quando eu pergunto como eu mesmo me experimento na experiência fática da vida: - sem teorias! (Heidegger, 2010, p. 17).

Podemos dizer, então, que, a partir desta preleção e no contexto dela em particular, Heidegger forja e estabelece uma peculiar fenomenologia da religião, que irá transpor para uma original interpretação das epístolas paulinas, particularmente a Epistola aos Gálatas (Heidegger, 2010, p. 61-67) e as duas Epistolas aos Tessalonicense (Heidegger, 2010, p. 78-103). Assim, estava aberto o caminho para Heidegger realizar uma investigação fenomenológica 
a partir de textos da tradiçáo religiosa da comunidade cristã originária. De fato, Heidegger mesmo a realizou na durante sua atuação na Universidade de Friburgo (Capelle-Dumont, 2012, p. 202-218).

Só a título de exemplo, concentraremos nossa atenção sobre um dos pontos fundamentais da interpretação heideggeriana das epístolas paulinas, que terá implicaçóes decisivas na elaboraçáo dos conceitos da analítica existencial de Ser e tempo (Pöggeler, 2001, p. 39-47; Mac Dowell, 1993, p. 126-140). Na primeira epístola paulina aos Tessalonicenses, Heidegger descobre que, com o advento da experiência cristá, surge uma nova concepção de escatologia. Esta palavra não significa mais uma "algo" por vir, muito menos num futuro distante e indeterminado, mas há nela uma relação com a parousia cristã em sentido propriamente originário (Heidegger, 2010, p. 87-94). Assim, a segunda vinda de Cristo não é a expectativa de um acontecimento futuro, mas o despertar para a iminência dessa vinda, tendo um significado kairológico. Esse tempo já está se realizando, no aqui e agora. Com efeito, ter uma relação com a parousia implica estar plenamente desperto no presente e não em expectativa de um acontecimento que ainda não chegou ou que, eventualmente, nunca chegará. O "quando" transforma-se, entâo, em "como viver" plenamente o presente (Vattimo, 2004, p. 151-167).

Em Fenomenologia da vida religiosa, Heidegger mostra que a temporalidade originária nasce da experiência fática da vida e, portanto, é um equívoco partir de "teorias" já prontas para "enquadrar" o tempo. Assim, como ele mesmo enfatiza, trata-se de não falsificar o problema do tempo, mas de ver o fenômeno do tempo a partir da vida fática. Está em jogo compreender o tempo de uma maneira "totalmente abstraída (ganz abgesehen) de toda consciência e tempo puros":

Enquanto o conceito 'temporal' ainda for tomado em sentido indeterminado, não se saberá absolutamente nada de que tempo se fala. Enquanto o sentido do 'temporal' ficar indeterminado, é possível tomá-lo como algo não prejudicativo (Präjudizierendes). Pode-se pensar: enquanto cada objetualidade se constitui na consciência, ela é temporal 
e, com isso, conquista-se o esquema fundamental do que é temporal. Porém, essa determinação 'geral' do tempo não é fundamental, mas uma falsificação do problema do tempo. Com isso é indicada uma moldura (Rahme) para o fenômeno do tempo, isto é, a partir do que é teorético (Theoretischen). Ao contrário, o problema do tempo deve ser compreendido da maneira como experimentamos originariamente a temporalidade na experiência fática - totalmente abstraída de toda consciência e tempo puros. O caminho, portanto, é inverso. Devemos perguntar ao contrário: o que é originariamente a temporalidade na experiência fática? $\mathrm{O}$ que significa, na experiência fática, passado (Vergangenheit), presente (Gegenwart) e futuro (Zukunft)? Nosso caminho parte da vida fática, isto é, parte da vida fática na medida em que o sentido do tempo possa ser conquistado. Com isso o problema do que é histórico está devidamente caracterizado e indicado (Heidegger, 2010, p. 60).

\section{Considerações finais}

Apesar das dificuldades de se recompor um possível texto original das preleçôes a partir de anotaçóes de alunos que assistiram às exposiçóes de Heidegger, não resta dúvida que nelas pulsa e está presente um modo de pensar muito original. Por esta razão, "Introdução à fenomenologia da religiāo" é de primordial importância para compreender seu pensamento inicial em relaçáo ao fenômeno religioso e, tratando-se de Heidegger, de uma concepção e busca por elaboração de uma peculiar fenomenologia da religião.

Enfim, por mais frequentes que tenham sido, há várias décadas, as referências às preleçôes sobre as epístolas paulinas, faltava uma clareza sobre suas bases textuais e sobre a precisão de sua argumentação, a que temos acesso a partir da publicação do volume 60 da obra completa heideggeriana, publicado somente em 1995, sob o título Fenomenologia da vida religiosa. Pois, como escrevem os editores Matthias Jung e Thomas Regehly:

A posição e o lugar temático que esta preleção ocupa no âmbito da obra heideggeriana definem-se pelo conteúdo e objeto da preleção: em nenhum outro lugar torna-se táo visível a natureza própria do 
preconceito filosófico em oposição ao método científico; em nenhum outro lugar trata-se com tal envergadura e exatidão exegética as questóes religiosas. Heidegger idealiza e arquiteta uma crítica da filosofia da religiáo contemporânea (Troeltsch) com consideraçóes fundamentais sobre o modo em que pode mostrar-se a experiência fática da vida em sua historicidade. $\mathrm{O}$ esclarecimento total do conceito metodológico fundamental de 'indício formal' (formale Anzeige) constitui o pano de fundo sobre o qual os documentos mais antigos do cristianismo originário são submetidos à investigação fenomenológica. No quadro dessa interpretação 'histórico-realizadora' ("vollzugsgeschichtlichen" Auslegung), Heidegger interpreta passagens escolhidas da Epístola aos Gálatas como também das Epístolas aos Tessalonicenses. Tomando por base o fenômeno da pregação paulina, segue elaborando dessa maneira as notas elementares da religiosidade cristã originária nas quais se torna visível o caráter de realização da vida fática enquanto tal (Heidegger, 2010, p. 323-324).

Por esta passagem, vemos que até mesmo os editores das preleçóes heideggerianas do semestre de inverno de 1920/21, oferecidas na Universidade de Friburgo, sob o título "1. Introduçãoà fenomenologia da religião", chamam atenção para dois elementos metodológicos intimamente interligados: o "indício formal" (formale Anzeige) e a "interpretação 'histórico-realizadora" ("vollzugsgeschichtlichen" Auslegung). Por meio desses elementos, Heidegger procura escapar aos enganos solipsistas da filosofia da consciência. Em suas preleçóes, busca alternativas de fugir à fenomenologia husserliana a que ele próprio inicialmente esteve associado. Via de regra, entendese o histórico como um processo temporal do que passou. Para Heidegger, porém, a própria experiência fática da vida é entendida como um processo que se dá no tempo, como um dar-se temporal na consciência. Para finalizar, retomemos um trecho da passagem citada anteriormente, onde Heidegger afirma: "Nosso caminho parte da vida fática, isto é, parte da vida fática na medida em que o sentido do tempo possa ser conquistado. Com isso o problema do que é histórico está devidamente caracterizado e indicado (Unser Weg geht vom faktischen Leben aus, von dem aus der Sinn von Zeit gewonnen wird. Damit ist das Problem des Historischen gekennzeichnet)" (Heidegger, 2010, p. 60). 


\section{Referências}

ALES BELLO, Angela. Culturas e religioes: uma leitura fenomenológica. Bauru: Edusc, 1998.

BARASH, Jeffrey Andrew. Heidegger e o seu século: Tempo do ser, tempo da história. Lisboa: Instituto Piaget, 1997.

CAPELLE-DUMONT, Philippe. Filosofia y teologia en el pensamiento de Martin Heidegger. Nova edição revista e ampliada. Buenos Aires: Fondo de Cultura Económica, 2012.

CAPUTO, John D. Desmitificando Heidegger. Lisboa: Instituto Piaget, 1998.

ESCUDERO, Jesús Adrián. El programa filosófico del joven Heidegger. Barcelona: Herder, 2008.

. Heidegger y la genealogía de la pregunta por el ser: una articulación temática y metodológica de su obra temprana. Barcelona: Herder, 2010.

El joven Heidegger. Asimilación y radicalización de la filosofía práctica de Aristóteles. Em Logos. Anales del Seminario de Metafísica, vol. 3, 2001, p. 179221.

El programa filosófico del joven Heidegger. (En torno a las lecciones de 1919. la idea de la filosofía y el problema de la concepción del mundo). Em Eidos: Revista de Filosofía de la Universidad del Norte, Barranquilla, Colombia, número 7, agosto 2007, p. 10-27.

. El joven Heidegger y los presupuestos metodológicos de la fenomenología hermenéutica. Em: Thémata. Revista de Filosofía. Universidad Autónoma de Barcelona, número 44, 2011, p. 213-238.

GADAMER, Hans-Georg. Hermenêutica em retrospectiva. Petrópolis: Vozes, 2009.

Verdade e método II. 2. ed. Petrópolis: Vozes, 2004.

GOTO, T. A. O fenômeno religioso: a fenomenologia em Paul Tillich. São Paulo: Paulus, 2004.

GRESCHAT, Hans-Jürgen. O que é ciência da religião? São Paulo: Paulinas, 2006.

GUIGNON, Charles B. (ed.). Poliedro Heidegger. Lisboa: Instituto Piaget, 2000. 
HEBECHE, Luiz A. O escândalo de Cristo: ensaio sobre Heidegger e São Paulo. Ijuí: Unijuí, 2005.

HEIDEGGER, Martin. Phänomenologie des religiösen Lebens. Frankfurt am Main: Vittorio Klostermann, 1995.

Vozes, 2010.

Fenomenologia da vida religiosa. Bragança Paulista: Edusf; Petrópolis: . Ontologie (Hermeneutik der Faktizität), Frankfurt am Main: Vittorio Klostermann, 1988.

. Ontologia (Hermenêutica da faticidade). Petrópolis: Vozes, 2012.

. Phänomenologische Interpretationen zu Aristoteles: Einführung in die Phänomenologische Forschung. 2. ed. Frankfurt am Main: Vittorio Klostermann, 1994.

Interpretações fenomenológicas sobre Aristóteles. Introdução à pesquisa fenomenológica. Petrópolis: Vozes, 2011.

. Interpretaciones fenomenológicas sobre Aristóteles: indicación de la situación hermenéutica [Informe Natorp]. Edição e tradução de Jesús Adrián Escudero. Madri: Trotta, 2002.

. Sein und Zeit. 16. ed. Tübingen: Max Niemeyer, 1986.

. Ser e tempo. Bragança Paulista: Edusf; Petrópolis: Vozes, 2006.

. Unterwegs zur Sprache. 11. ed. rev. Stuttgart: Günther Neske, 1997.

. A caminho da linguagem. 3. ed. Bragança Paulista: Edusf; Petrópolis: Vozes, 2003.

. Zur Sache des Denkens. Tübingen: Max Niemeyer, 1969.

Sobre a questão do pensamento. Petrópolis: Vozes, 2009.

HEIDDEGER, Martin e JASPERS, Karl. Briefwechsel 1920-1963. Munique e Frankfurt. Piper e Vittorio Klostermann, 1992.

HUSSERL, Edmund. Logische Untersuchungen (vol. I e II). La Haye: M. Nijhoff, 1984.

Investigaçôes lógicas (vol. 1 e 2). Rio de Janeiro: Forense Universitária, respectivamente 2014 e 2012. 
Zur Phänomenologie des inneren Zeitbewusstseins (1893-1917). Haag: Matinus Nijhoff, 1966.

. Liçóes para uma fenomenologia da consciência interna do tempo. Lisboa: Imprensa Nacional; Casa da Moeda, 1994.

MAC DOWELL, J. A. A gênese da ontologia fundamental de M. Heidegger: ensaio de caracterização do modo de pensar de 'Sein und Zeit'. São Paulo: Loyola, 1993.

MACHADO, J. A. T. Os indícios de Deus no homem: uma abordagem a partir do método fenomenológico de Martin Heidegger. Porto Alegre: Edipucrs, 2006.

Nunes, Benedito; Campos, Maria José (org.). Hermenêutica e poesia: o pensamento poético. Belo Horizonte: Editora da UFMG, 2007.

OTT, Hugo. Martin Heidegger: a caminho de sua biografia. Lisboa: Instituto Piaget, 2000.

PERAITA, Carmen Segura. Hermenéutica de la vida humana: em torno ao Informe Natorp de Martin Heidegger. Madri: Trotta, 2002.

PÖGGELER, Otto. A via do pensamento de Martin Heidegger. Lisboa: Instituto Piaget, 2001.

. Heidegger: Perspektiven zur Deutung seines Werkes. Frankfurt am Main: Athenäum, 1984.

. Neue Wege mit Heidegger? Em Philosophische Rundschau, 29. Jahrgang, Tübingen: J.C.B. (Paul Sieback), 1982, p. 39-71.

RICHARDSON, William J. Heidegger: Through Phenomenology to Thought. The Hague: M. Hijhoff, 1963 (reediçóes de 1967 e 1973).

SAFRANSKI, Rüdiger. Heidegger: um mestre da Alemanha entre o bem e o mal. São Paulo: Geração Editorial, 2000.

SANTOS, Bento Silva. Fenomenologia e Idade Média. Curitiba: CRV, 2013.

STEIN, Ernildo. Compreensão e finitude: Estrutura e movimento da interrogação heideggeriana. Ijuí: Unijuí, 2001.

SOKOLOWSKI, Robert. Introdução à fenomenologia. 3. ed. São Paulo: Loyola, 2012.

VATTIMO, Gianni. Depois da cristandade: por um cristianismo náo religioso. Rio de Janeiro: Record, 2004. 
VAN DER LEEUW, Gerardus. Phänomenologie der Religion. 4. ed. Tübingen: J.C.B. Mohr (Paul Siebeck), 1977.

Fenomenologia de la religión. México: Fondo de Cultura Económica, 1964.

VELASCO, Juan Martin. Introducción a la fenomenología de la religión. 7. ed. Madri: Trotta, 2006. 